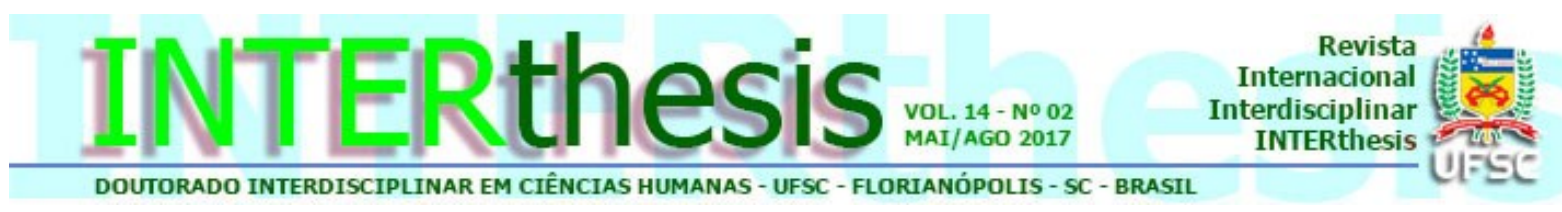

\title{
A CONSTRUÇÃO DA MEMÓRIA SOCIAL DAS PRODUÇÕES ARTÍSTICAS NA SAÚDE MENTAL PÓS REFORMA PSIQUIÁTRICA NO BRASIL
}

\author{
Renata Caruso Mecca ${ }^{1}$ \\ Diana de Souza Pinto ${ }^{2}$
}

Resumo:

Desde a Reforma Psiquiátrica no Brasil, surgiram muitos grupos artístico-culturais na saúde mental que contribuem para a construção da participação sociocultural da população atendida. A memória social dessas produções se constrói em meio a disputas de sentido, coloca em destaque o jogo de forças entre diferenças potenciais que lutam para se afirmar e prevê dar lugar ao novo. Por meio de uma reflexão crítica sobre textos que descrevem experiências emblemáticas na interface da arte e da saúde mental, evocamos elementos que sugerem duas formas de contribuição desses relatos para a construção da memória dessas produções: como trabalho e como invenção. A memória como trabalho é utilizada como instrumento de transformação social e se faz por meio da militância de atores que constroem visibilidade e apostam numa transformação das concepções sobre loucura. A memória como invenção é propulsionada pela qualidade intensiva dos encontros entre os atores e pela afetação que as produções promovem. Conjuga fluxos de desejo e experiências estéticas que deslocam identidades e engendram um campo de invenção permanente de formas de recepção desta produção. Conclui-se que esse processo evidencia um tensionamento entre uma dimensão molecular da memória, que se abre para a transversalidade das concepções de arte e loucura, transformando o mapa do perceptível, e uma dimensão molar, que enfatiza as tendências de categorização em segmento específico, ou como produção diretamente vinculada a um efeito social esperado pelas iniciativas da Reforma Psiquiátrica contra a estigmatização da loucura.

Palavras-chave: Arte. Saúde Mental. Memória. Cultura.

\section{INTRODUÇÃO}

Desde que as práticas de atenção psicossocial se afirmaram como paradigma para a política pública em saúde mental no país, surgiram muitos grupos artísticoculturais na saúde mental que configuraram um novo momento da relação loucura e

\footnotetext{
1 Doutoranda do Programa de Pós-Graduação em Memória Social na Universidade Federal do Estado do Rio de Janeiro, Rio de Janeiro, RJ. Professora do curso de Terapia Ocupacional da Universidade Federal do Rio de Janeiro, Rio de Janeiro, RJ, Brasil. E-mail: meccadasartes@yahoo.com.br

2 Doutora em Saúde Mental Professora-Associada no Programa de Pós Graduação em Memória Social da Universidade Federal do Estado do Rio de Janeiro, RJ, Brasil. E-mail: dianap@globo.com
} 
sociedade e que contribuíram para a construção da participação sociocultural da população atendida, implicando uma mudança da sensibilidade coletiva.

Um conjunto de produções artísticas se consolidou por meio de projetos autônomos ou de iniciativas dentro dos serviços de saúde mental que ambicionavam promover a ampliação da circulação social e o exercício da cidadania para uma população há muito desprovida de seus direitos fundamentais. Logo, processos que usavam a arte como recurso terapêutico deram espaço a projetos ancorados na construção de estratégias de saída das instituições de cuidado para integrar o circuito cultural das cidades.

Uma política pautada no reconhecimento da cultura como direito social básico e na valorização da diversidade cultural como patrimônio orientaram ações, em 2007, do Ministério da Cultura (MinC) em parceria com a Fundação Oswaldo Cruz FIOCRUZ. Ambos os orgãos organizaram uma oficina para a construção de uma política de fomento a produções na interface entre a arte e a loucura que culmina, em 2009, no Edital de premiação "Loucos pela Diversidade" que mapeou produções por todo o território nacional, sendo a maioria das experiências oriundas de pessoas físicas e grupos autônomos (AMARANTE et. al., 2012).

Na maior parte dos Centros de Atenção Psicossocial, o recurso artístico ainda é utilizado predominantemente com fins terapêuticos e de modo superficial no que tange ao entendimento dessas experiências como produtoras de linguagens e à sua valorização estética. Ainda assim, muitos dos projetos e propostas, especificamente aqueles oriundos de iniciativas autônomas, instauram uma experiência em arte numa relação crítica e dialógica como funcionamento do Sistema de Arte, criando formas paralelas e mais democráticas de difusão (LIMA, 2009; BARBOSA, 2010; GALVANESE; NASCIMENTO; D'OLIVEIRA, 2013).

A memória dessas produções também se constrói por meio de diferentes discursos presentes nos textos que descrevem as experiências dos projetos na interface da arte e da saúde mental. Pode ser compreendida como tessitura de afetos e expectativas diante do devir e utilizada como foco de resistência e instrumento de transformação social (GONDAR, 2015). Nessa interface, o campo da memória social foi sendo construído inicialmente sob uma perspectiva de preservação de uma memória autêntica com base em quadros sociais estáveis e valorizada em sua dimensão instituída formada por abstrações gerais, 
representações que ganham consenso e reconhecimento social. Contudo, a perspectiva adotada neste trabalho é distinta, pois enfoca o processo instituinte de construção da memória. Coloca em destaque o jogo de forças entre diferenças potenciais que lutam para se afirmar e prevê dar lugar ao novo, ao próprio processo de diferenciação. Na sua dimensão ética, se articula à criação, ao que nos afeta e nos faz apostar em outro campo de possíveis. Destaca-se que essa abordagem não desconsidera as representações, mas as toma como efeitos provisórios de um processo em que forças estão em encontro, choque e ebulição.

Diferentemente de seus contemporâneos, que apreendem o social em seus estados atualizados mais visíveis, Gabriel Tarde (2000) questiona as pequenas engrenagens de diferentes intensidades que o constituem e o alteram, sua dimensão molecular. Estas forças se conjugam e se propagam em fluxos de crenças e desejos de um indivíduo para o outro até alcançarem a consistência social que Ihes dê visibilidade, sua dimensão molar.

Crenças e desejos são quantidades que se associam a uma idéia, um objeto, uma percepção, imitadas em fluxos que se expandem pela afetação que produzem nos indivíduos. Os fluxos se confrontam e se adaptam produzindo invenções que, ao serem imitadas extensivamente, tornam-se abstrações gerais. Toda abstração geral se inicia com uma invenção singular que se propaga por contágio.

O binômio imitação-invenção explica a teoria da memória em Tarde. Enquanto a imitação dá consistência e institucionaliza os símbolos e ritos sociais, a invenção é a potência renovadora, nômade, que abre uma nova variação no enredo da vida social e passa a se propagar pela imitação (THEMUDO, 2002).

Realizamos uma revisão bibliográfica nas bases de dados Lilacs, Medline e BVS de artigos brasileiros publicados em periódicos indexados do ano 2000 a 2014 , utilizando os descritores: arte, saúde mental e cultura. Elencamos 48 artigos, dos quais selecionamos aqueles que se referiam ao uso da arte para participação sociocultural da população atendida na saúde mental. Excluímos artigos relacionados ao uso da arte como recurso terapêutico somente ou aqueles que abordavam a relação entre a arte e saúde mental no Brasil antes da Reforma Psiquiátrica, totalizando 16 artigos utilizados. Compuseram, também, dessa revisão, livros, textos em coletâneas e catálogos. Posteriormente, analisamos o material levantado a partir das categorias da memória concebidas como trabalho e invenção. 
Objetivamos colocar em evidência elementos presentes nos discursos sobre as produções na interface da arte e da saúde mental que contribuem para o processo de construção de sua memória e que desvelam um tensionamento. De um lado, uma memória como trabalho calcada nas forças do ativismo da Reforma Psiquiátrica contra a hierarquização e a institucionalização do cuidado e da loucura. Destacamos os seguintes elementos que a constituem: as estratégias discursivas e manobras estéticas utilizadas pelos autores para modificar estigmas e reinventar sentidos de loucura, valores e atores do passado acionados no presente para manter vivo o processo de Reforma.

De outro lado, uma memória como invenção que dá a ver as possibilidades de transversalidade que essas práticas de interface promovem, afirmando as diferenças e transformando o mapa do perceptível. A qualidade intensiva dos encontros, o poder de afetação das produções, e as hibridizações e quebras de identidades resultantes dos processos de criação e fruição são os elementos que contribuem para essa memória como invenção.

Tomamos os elementos acima apresentados para a análise das experiências relatadas e os associamos às dimensões molar e molecular do processo de construção da memória. A dimensão molecular refere-se às pequenas forças infrarepresentacionais que se negam/afirmam, atraem/repulsam que constituem a zona de agitação na qual invenções eclodem e seguem em novas séries imitativas. São tendências em maior ou menor grau de agitação e propagação que são condição de possibilidade de engendramento das dimensões molares do social e de sua metamorfose (THEMUDO, 2002).

A dimensão molar refere-se aos estados transformados em entidades de representação, conjuntos de designos, idéias, costumes e julgamentos, resultantes provisórios desses fluxos imitativos, atualizados em modos finitos palpáveis (LAZZARATO, 2002).

Ambas se apresentam nas descrições sobre os projetos. Porém, algumas destas enfocam o efeito molar, ou seja, as mudanças nas representações sobre a loucura e sua reverberação no público. Outras priorizam o plano molecular constituído por pequenas composições e transformações que são condição para o engendramento de outras possibilidades de recepção e categorização dessas produções, menos subservientes a uma intencionalidade militante. 


\section{MEMÓRIA COMO TRABALHO}

A memória como trabalho se dá pela atividade de atores do campo da Saúde Mental que, afetados pela potência transformadora dessas experiências, constroem visibilidade e apostam num cenário em que as maneiras de fazer e os modos de existência dos sujeitos em questão se sustentem em espaços além do âmbito da saúde. Mas este trabalho não culmina numa memória única e estável; ele pressupõe conflitos entre diferentes visões sobre arte, cultura e sofrimento psíquico, bem como sobre quais estratégias devem ser empregadas no sentido de desestigmatização e construção da participação sociocultural desta população (JELIN, 2002).

No campo das políticas públicas em saúde mental, hoje vivemos momentos em que urge reconvocar os valores e princípios da Reforma Psiquiátrica e fazer dela um movimento vivo em permanente construção. Manifestações contra políticas assistencialistas de cunho asilar e curativo, debates sobre a crescente fabricação de doenças psiquiátricas e apelos pela expansão da Rede de Atenção Psicossocial tornam-se frequentes e atualizam, no presente, os valores da luta contra os processos de institucionalização e isolamento.

Alguns dos projetos criados nas últimas décadas constituem processos de desinstitucionalização de hospitais psiquiátricos, eixo central da assistência em saúde mental antes da reforma. Articulam diversas linguagens da arte como ferramenta no resgate da dignidade humana e do sentimento de pertencimento à cidade pela contribuição à cultura local. A "Rádio Tamtam", programa de rádio local da cidade de Santos, feito pelos usuários dos serviços de saúde mental "loucutores" (como se autodenominavam), é um exemplo de tais projetos. Segundo Di Renzo (2011, p.153), ela fez com que "a linguagem do excluído ecoasse na sociedade, rompendo paradigmas e preconceitos".

Em alguns trabalhos, a loucura e o sofrimento são temática central das produções que objetivam desestigmatizar por meio de operações estéticas discursivas. Assim, a mudança do imaginário social sobre a loucura é o efeito esperado da recepção desses trabalhos pelo público.

Os relatos que seguem integram as produções acadêmicas selecionadas e referem-se a um trabalho de memória militante sobre as representações da loucura 
na sua dimensão molar. Seu efeito são os novos signos inventados que se propagam na cultura local, afirmando a loucura como experiência do humano e criando uma tradição alinhada à Reforma que norteia o universo temático e simbólico das produções artísticas.

Alguns grupos se mantém em evidência no cenário cultural brasileiro, como o "Cancioneiros do IPUB" e o "Harmonia Enlouquece". Trabalham na dimensão molar, pois os conteúdos de suas obras partem das histórias de vida, de sofrimento e discriminação de seus autores e são colocados em debate como experiência do humano e das relações sociais (AMARANTE; COSTA, 2012; VIDAL, 2011).

O Festival da Loucura de Barbacena - MG possibilita à cidade enfrentar o estigma de "Cidade dos Loucos" e rever padrões culturais de representação simbólica da loucura. Utiliza o humor para deslocar a concepção de loucura como doença e periculosidade e evoca o trabalho de Nise da Silveira por meio da exposição do acervo do Museu Imagens do Inconsciente como oposição aos métodos violentos de tratamentos psiquiátricos já usados (BOTTI; TORRÉZIO, 2014).

A valoração dessas produções e sua legitimação como patrimônio cultural consituem um processo que inclui conflitos e tensionamentos. De um lado, práticas políticas afirmativas que, por objetivar dar lugar a produções à margem do sistema da cultura, produzem prêmios e mostras específicos para arte de pessoas da saúde mental que, por vezes, servem a uma lógica classificatória, correlacionando arte e loucura de maneira direta. Por outro, essas mesmas políticas promovem negociações e articulações de diferenças culturais que abrem espaços de experiências coletivas e de subjetivações, constituindo um outro processo de enunciação e de produção de mais cultura (BARROS; ALMEIDA; VECCHIA, 2007). Nessa perspectiva, a memória como trabalho é compreendida como ferramenta para fazer vivos e continuamente reinventados os princípios da Reforma Psiquiátrica e da diversidade cultural, no sentido de uma memória ativa, incorporada ao social.

O portal "(En)cena: saúde mental em movimento" produz um banco de dados e publiciza experiências e produções artísticas oriundas dos serviços de saúde mental para modificar, no nível cultural, os estigmas e as relações verticais presentes no modelo asilar de cuidado em saúde mental. Com isso, estimula produções que ultrapassam a ordem técnico-acadêmica e transversaliza as temáticas ligadas à 
loucura (RAMOS et al., 2012). No que tange ao molar, trabalha especificamente com a temática da saúde mental, porém entende que esta é de conhecimento transdisciplinar e, assim, convida a produção de textos de quaisquer pessoas que tragam a saúde mental como eixo transversal, tornando porosos os domínios que a compreendem em nível molecular. O projeto cultural "Cartografias da Criação" opera nessa dimensão, mapeando e difundindo a produção em arte de pessoas com sofrimento psíquico, investindo na multiplicidade de processos criativos e na pesquisa de linguagens artísticas inovadoras que surgem deste território.

São projetos que trabalham no intuito de difundir e garantir acesso às políticas culturais, em meio a disputas e negociações de sentidos, num jogo político produtor de memórias. Colocam em debate temas ligados às artes e à saúde mental para um público ampliado, utilizando práticas para deslocar e reinventar sentidos de loucura e de arte, legitimando uma produção oriunda do campo da saúde mental como produção de cultura.

Jelin (2002) compreende memórias como processos subjetivos e como objeto de disputa, incluindo o poder ativo dos atores na produção de sentido em meio a lutas de poder, que ela denomina trabalho de memória. Coloca em evidência a implicação política desse trabalho, já que a reflexão e a análise crítica inerentes a ele são ferramentas oferecidas aos atores sociais, especialmente os excluídos, e constituem um processo de empoderamento.

Assim, consideramos o trabalho de memória desses atores como produção de visibilidade para as produções artísticas e como resistência a toda forma de enclausuramento, de normalização, afinada com a dimensão sociocultural da Reforma Psiquiátrica. Esta preconiza a produção de uma nova cultura que comporte a loucura como condição inerente e componente da diversidade humana, que faz interseção com os diversos campos do universo da existência, fonte de vida e criação. Esse sentido de loucura, na sua dimensão molar, passa a ser cultivado, propagado e assumido como direito de cidadania (SILVA et al., 2012 ; RAMOS et al., 2012; SANTOS; ROMAGNOLI, 2012).

Dado que os princípios e valores da Reforma Psiquiátrica constituem uma força social que tem importância estratégica e paradigmática em nossa época, a memória como trabalho pode tomar a direção de um hábito ao pressupor a transformação nas concepções sobre a loucura como função dessas produções artísticas e como efeito 
esperado de sua recepção pelo público. E, assim, enraizar a dimensão antiestigmatizante das linguagens artísticas oriundas desse território em tradição (TARDE, 2000; RANCIÈRE, 2012).

\section{MEMÓRIA COMO INVENÇÃO}

A memória como invenção se destaca quando colocamos uma lupa sobre os processos infinitesimais que constituem os encontros contingentes, entre a potência de vida e a invenção que emanam dessas produções, dos artistas, dos profissionais envolvidos nesses projetos e do público. Nesse sentido, a teoria de Gabriel Tarde nos ajuda a pensar o plano dos afetos que instaura esses encontros. $O$ que nos afeta é, antes, uma nova sensação, uma nova palavra, uma experiência criativa singular que rompe com a reiteração das mesmas idéias e modos de sentir e deflagra o processo de memória, momento que o autor denomina de invenção, entrecruzamento de fluxos de crença e desejo. Uma invenção propagada em séries imitativas constitui uma singularidade repetida até o limite de uma nova invenção que promove uma divergência na série inicial, que se bifurca, originando diferentes vias de desenvolvimento (TARDE, 2000; THEMUDO, 2002).

As passagens que seguem são relatos em produções acadêmicas de encontros inventivos constelados nesse campo que, ao evidenciar o plano molecular, provocam rupturas nas tradições inventadas pelo movimento da Reforma. Investem na experiência de criação que resiste a categorizações que prédeterminam um destino ao que se gesta na ebulição dos processos criativos e na afetação que desestabiliza esses mesmos contornos.

Essa afetação aflora no relato de Di Renzo (2011) ao narrar episódios da intervenção no Hospital Anchieta de Santos como cenas de um espetáculo, cenas de encontro com o pulsar da vida ainda humano, apesar de todo desgaste do confinamento. Essas experiências foram propulsoras das intervenções do projeto Tamtam que, segundo o autor, não implicavam o elogio da loucura nem uma relação utilitária, mas apontavam para a dimensão estética como plano de ação, comprometida com processos existenciais de criação de si e do mundo, que se fazem por um experimentalismo intensivo e por uma ousadia de invenção permanente de formas de estar no mundo. 
Interessa ao trabalho do Coletivo de Rádio "Potência Mental" a experiência de produção radiofônica pelo "encontro louco de pessoas", de maneira que a loucura revela-se fora das pessoas e é alocada no encontro. A renúncia tanto à dimensão terapêutica quanto anti-estigmatizante enquanto núcleos temáticos centrais das produções marca sua singularidade, rompendo também com a tradição de insistir na importância de programas serem produzidos inteiramente por pessoas em situação de sofrimento psíquico. Para os autores, essa insistência mantém a dicotomia responsável pela discriminação dos diferentes. (STREPPEL; PALOMBINI, 2011).

No domínio molar mais visível e no sentido de uma memória trabalho, o coletivo carnavalesco "Tá pirando, pirado, pirou!" configura-se como importante dispositivo de desestigmatização da loucura, de criação de visibilidade e debate junto à sociedade. Porém, ao analisarmos a dimensão molecular, a insersão e a permanência dos profissionais de saúde mental e usuários no coletivo também ocorrem por outras razões, pois é um espaço que possibilita a todos os envolvidos nos processos de criação viver outros papéis e outros lugares, mais abertos a ressignificação: usuário vira sambista, psicóloga, porta-bandeira; todo mundo é folião.

Os fluxos de desejo que produzem esses encontros geram hibridizações, quebras de hierarquias e de identidades, não somente a do "doente mental", mas a dos profissionais de saúde, já que a produção de cuidado pelos profissionais é também uma prática de si. A criação passa a ser vetor existencial que mobiliza todos os integrantes dos grupos, inclusive aqueles que, na qualidade de espectadores, entram em contato com essas produções (XISTO, 2011).

Num estudo sobre o público de apresentações de teatro com atores com histórico de sofrimento psíquico, Milhomens e Lima (2014) referem que a qualidade estética do espetáculo chama atenção do público e o surpreende, deslocando o olhar da loucura para os elementos artísticos. O público se emociona com a diversidade dos grupos e a forma como interagem e se vê provocado a integrar os espetáculos movido pela percepção de sua própria diferença e pelo desejo de viver com mais intensidade.

A proposta do grupo autônomo "Coral Cênico Cidadãos Cantantes" é trabalhar em um coletivo de composição heterogênea. Por meio do convívio com a diferença, trilha-se o caminho da inclusão sociocultural. Sua singularidade reside na 
capacidade de provocar encontros no espaço público, se deparar com o inusitado, com as fraturas ocasionadas pelos sujeitos invisíveis que habitam uma metrópole esvaziada de encontros (MALUF et al., 2009).

Nesses grupos, loucura e sanidade se deslocam do lugar de opostos simétricos criando um território cultural livre para acolher corpos, afetos e linguagens. Contrariamente à busca para demarcar quem pertence a um grupo cultural fechado, eles visam a afirmar o direito à diversidade e atualizam devires de todos os envolvidos. A adesão dos integrantes e a afetação que produzem no público relacionam-se ao campo aberto de possibilidades de invenção de novos modos de existir.

Evoca-se, nessas publicações, as mudanças na sensibilidade provocadas pelas experiências singulares e pelas práticas de si que configuram forças moleculares de atração, propulsoras do contágio necessário à propagação da memória. Embarcadas nos fluxos de desejo pela diferença e pela intensificação da vida, expandem-se, tencionando as formas seletivas de categorização do campo artístico-cultural e as tradições do movimento da Reforma tornadas hábito.

O encontro entre as séries imitativas acidentalmente atualiza um outro possível entre mil outros diferentes dele e, assim, amplia a possibilidade de diferenciação e variação das idéias, percepções, modos de agir, etc. Desta maneira, a memória como invenção tende a deslocar as produções dos temas, das categorias e da função a que estão tradicionalmente articuladas. Abre-se a outras possibilidades de apreensão e significação das produções, menos subserviente aos hábitos de valoração calcados na sua utilidade para fomentar uma mudança necessária à emancipação da loucura.

\section{DISCUSSÃO: DIMENSÕES MOLAR E MOLECULAR DA MEMÓRIA}

Pensamos que muitas formas de leitura são possíveis para as produções artísticas realizadas na interface da arte e da saúde mental. E a construção de sua memória passa pelo tensionamento entre os níveis molar e o molecular.

O nível molar é constituído por referências representacionais e grandes identidades, estados visíveis provisórios resultantes da composição e disputa entre intensidades moleculares. Nesse nível, os grupos se envolvem em circunscrições e 
entram em relações de força que lhes dão uma figura de identidade cujas causas são motor de militância. Identificamos essas referências molares no trabalho de crítica dos atores sobre a dimensão instituída das concepções de loucura e sua relação com a arte. Estas enfocam suas raízes psicopatológicas, seus efeitos terapêuticos ou sua característica ingênua. Também as observamos na relação causal que esses atores estabelecem entre formas de arte e função antiestigmatizante, assim como privilegiam as formas de leitura que priorizam os potenciais efeitos sociais das obras.

Os atores inventam uma tradição em que a linguagem artística é uma estratégia para modificar as representações acerca da loucura. A função da memória consiste em atualizar e difundir valores da Reforma no presente, seguindo os fluxos de imitação de grande parte das iniciativas culturais ligadas ao campo da saúde mental. Em manifestações culturais do Movimento da Luta Antimanicomial, o sentido da palavra manicômio é ampliado para além das instituições psiquiátricas e refere-se a toda experiência de aprisionamento a padrões de normalidade a serem consumidos e de enquadramento das subjetividades a práticas de controle capilarizadas.

A exposição e a leitura dessas obras também podem ser utilizadas para criar sentidos de loucura associados à liberdade, à criação e à arte, assim como a concepções de saúde mental desvinculadas do cuidado da doença e associadas a práticas de qualidade de vida e respeito às diferenças. Nas manifestações da Luta Antimanicomial, por exemplo, Profeta Gentileza, Artur Bispo do Rosário e a psiquiatra Nise da Silveira são personagens constantemente evocados, assumindo um teor "aurático". Determinadas características dessas personagens são enfatizadas para expressar um sistema de valores condizente com a Reforma, importando sua eficácia num mercado de bens simbólicos.

Aproximações que autores fizeram, no passado, dessas produções com arte bruta, ou qualquer outra classificação, são criticadas no presente, pois sufocam os possíveis outros sentidos. Segundo esse ponto de vista, corre-se o risco de abandonar uma leitura psicopatológica da arte e adotar uma outra categoria de arte específica para pessoas que estão à margem, instaurando uma outra forma de clausura (SIMÕES, 2008; MALUF et al., 2009; THOMAZONI; FONSECA, 2011). 
Talvez hoje se evite classificar essas obras em categorias específicas, mas ainda assim, em grande parte das manifestações, esperam-se efeitos da recepção destes trabalhos no imaginário social sobre a loucura. Visando este efeito, colocam a redefinição das concepções e do lugar da loucura como tema central das produções e, assim, acabam por reduzir as possibilidades de diálogo e interpretação de todo um conjunto múltiplo e diversificado de linguagens que emerge desse território. Ao operar apenas no nível molar, a memória perde a processualidade e estabelece uma relação de causalidade entre os valores da Reforma, as intenções dos artistas e a recepção pelo público (RANCIĖRE, 2012).

O nível molecular diz respeito a emergências do real que correspondem a virtualidades não redutíveis a identidades ou unidades fixas e que sempre diferem daquilo que está atualizado. Neste caso, referimo-nos ao modo como a leitura e o discurso sobre essas produções podem se abrir ao plano subrepresentacional de variações do existir e da potência de agir, que atualiza devires, desloca posições e transversaliza os eixos arte e loucura ou arte e saúde.

Ao discorrer sobre as obras participantes da Mostra "No Centro da Vida", Branco (2009) e Wanderley (2009) colocam que ela busca criar zonas de encontros poéticas/criativas em algum lugar entre a razão e a desrazão. Instaura-se em um corpo de práticas de cuidado com o outro, resultantes dos processos de reforma, que acirraram as discussões acerca do lugar e da visibilidade daqueles que, pela diferença, não se encaixam no modelo "macho-branco-rico-europeu". Os autores sublinham o envolvimento dos profissionais comprometidos em lidar com essas adversidades, a emoção que circula entre os autores que enfrentam, e as obras que presentificam o incompreensível, o humano que desvia e que está em todos nós, em latência, como potência de vida e invenção.

A leitura de Branco (2009) ilumina a dimensão do encontro como campo de possibilidades para que os artistas tragam à tona um pouco do que verdadeiramente somos feitos: de desejo e sonho. Uma vez que a combinação da presença de todos os envolvidos "multiplica e reverbera o possível, em termos de energia, do que emana e se troca nesses encontros reais: que são por assim dizer a nossa própria obra aqui e então".

Essas intepretações se aproximam da concepção probabilística do real para Tarde. O real é um campo virtual de excesso de potência, conjunto de possíveis não 
realizáveis, composto pela intensidade das ações moleculares de existência impessoal. Estas constituem matéria subrepresentativa e, como tal, remetem aos fluxos e ondas de crenças e desejos que se dão em séries repetitivas. O que existe, na realidade, portanto, são emergências produzidas pelos encontros fortuitos destes fluxos, que escapam à necessidade e à causalidade e ocorrem por acidente. Estes encontros acidentais produzem o mundo que nos rodeia, povoado de virtualidades que não se esgotam pelo trabalho da razão e da causalidade. (VARGAS, 2000; THEMUDO, 2002).

A invenção possibilita a emergência de outros possíveis que resistem às conformidades das tradições e da racionalidade. Ao expandir-se pela imitação, motor de prolongamento desta singularidade em séries sociais, pode ganhar consistência molar e tornar-se hábito. Mas também suscita invenções mais complexas, produzindo um jogo cada vez mais variado de iniciativas que se combinam cada vez melhor entre elas. Estas ganham mundos e tornam-se força de ruptura com modos instituídos de pensamento e percepção. (TARDE, 2000; VARGAS, 2000).

Nesse sentido, ao construir memória para essas produções artísticas, criar uma tradição é o que menos importa; manter o plano do encontro aberto a invenções e alargar o campo do possível parece-nos crucial.

Para Liberato e Dimenstein (2013), pensar a arte no contexto da Reforma Psiquiátrica é refletir sobre sua potencialidade como dispositivo de transformação, mas também indagar sobre os perigos de sua utilização como ferramenta de reprodução e sobrecodificação da existência. A experiência artística é compreendida como produtora de singularidades, colocando-se a serviço da experimentação de novas sensações por meio dos fluxos estéticos, em um paradigma também ético e político no sentido apontado por Rancière (2012), de reconfiguração dos regimes de visibilidade que modifica a paisagem da vida coletiva.

Subverter significados associados à loucura pode se tornar uma tradição, oficializando uma memória e uma forma de leitura dessas produções, caso esta subversão e os princípios da Reforma antecedam a toda experiência de contato imediato com as produções artísticas e se tornem um efeito esperado da recepção estética (RANCIĖRE, 2012). Na exposição e difusão dessas obras, a forma de fazer prevalece sobre o significado das mesmas. Assim preconiza-se o investimento em 
formas de fazer que constituam um lugar digno para obras com marcas expressivas que subvertem normas estéticas e culturais estabelecidas, à altura de seu processo de criação. (LIMA et al., 2009; CASTRO et al., 2011; LIMA; ISODA; CASTRO, 2012; CASTRO et al.,2013).

\section{CONSIDERAÇÕES FINAIS}

Transpor barreiras entre os campos da saúde e da cultura para produzir participação social, deslocar e balizar concepções sobre arte são movimentos que se engendram nesse momento no campo da interface da arte e da saúde mental e que promovem conflitos, por vezes tencionando políticas afirmativas para pessoas com sofrimento psíquico e, por vezes, tendem a transpor categorizações e acessar a loucura e arte como experiências do humano.

A contribuição dos relatos das experiências de projetos na referida interface para o processo de construção da memória dessas produções foi analisada em duas vertentes. A primeira evidencia uma memória como trabalho que se faz por meio da militância de atores que, engajados na dimensão sociocultural da Reforma Psiquiátrica, criam dispositivos para dinamizar as noções de loucura e para empoderar as experiências pela intersetorialidade com a cultura.

A segunda evidencia o plano dos afetos e do contágio que produz uma memória inventiva, conjugada por fluxos de desejo e experiências estéticas que atualizam devires de todos os envolvidos no processo criativo deslocando identidades. Produzem invenções que transversalizam a arte, a clínica e o sofrimento, constituindo estratégias de resistência na esfera da produção de subjetividade e de abertura de fendas na cultura (BARBOSA, 2010).

A memória dessas produções artísticas é construída entre os domínios molar e molecular. No que se refere ao molar, apontamos o trabalho dos atores sobre a dimensão instituída das concepções de loucura e as tendências de vinculação dos trabalhos a um efeito social esperado pelas iniciativas da Reforma Psiquiátrica contra a estigmatização da loucura. No que se refere ao molecular, enfocamos o campo de forças engendrado nos encontros entre os atores e as potências de vida e invenção. Intensidades que colocam em movimento as pequenas percepções, composições e criações. Estas se propagam ampliando as possibilidades de leitura dessas produções e transformando o mapa do perceptível e do pensável. 


\title{
THE CONSTRUCTION OF THE ARTISTIC PRODUCTIONS SOCIAL MEMORY IN BRAZIL'S THE MENTAL HEALTH FIELD POST-PSYCHIATRIC REFORM
}

\begin{abstract}
:
Since the Psychiatric Reform in Brazil, many artistic groups have emerged in the mental health field contributing to the social and cultural participation construction of the assisted population. The social memory construction of these productions occurs among disputes of concepts, highlights a set of tensions between potential differences that fight for reassuring themselves, and aims at opening up to the new. By critically reflecting on texts that describe projects in the interface between art and mental health, we point out elements that suggest two ways for the construction of these projects social memory: as work, and as invention. Memory as work is used as an instrument for social transformation and results from the actors' militancy, as they build visibility and rely on collective sensibility changes regarding concepts about madness. Memory as invention is enhanced by the intensive quality of the encounters among actors and also by the productions impact. The article articulates flows of desire and aesthetic experiences that shift identities and creates a field of reception ways permanent invention.This process highlights a tension between a memory molecular dimension that opens its horizons for the transversal conceptions of art and madness, by attesting its differences, and it transforms the map of what is perceivable and also the molar dimension, that emphasizes the trends towards categorizations of specific sectors, or as a production which is directly related to the expected social effects produced as a result of the Psychiatric Reform initiatives.
\end{abstract}

Keywords: Art. Mental Health. Memory. Culture

\section{LA CONSTRUCCIÓN DE LA MEMORIA SOCIAL DE LAS PRODUCCIONES ARTÍSTICAS EN LA SALUD MENTAL TRAS LA REFORMA PSIQUIÁTRICA EN BRASIL}

\section{Resumen:}

Desde la Reforma Psiquiátrica en Brasil, han aparecido muchos grupos artísticoculturales en el campo de la salud mental que han contribuido para el desarrollo de la participación sociocultural de la población atendida. La memoria social de esas producciones viene siendo construida en un contexto de discusiones sobre su sentido, poniendo de relieve el juego de fuerzas entre diferencias potenciales que luchan por afirmarse, y anuncia el surgimiento de algo nuevo. Mediante una reflexión crítica sobre textos que describen experiencias emblemáticas en la conexión entre el arte y la salud mental, evocamos elementos que sugieren dos formas de contribución a la construcción de la memoria de esas producciones: como trabajo y como invención. La memoria como trabajo se utiliza como instrumento de transformación social y ocurre a través de la militancia de actores que crean visibilidad y apuestan por una transformación de los conceptos de locura. La memoria como invención es estimulada por la alta calidad de los encuentros entre los actores y por la afectación que las producciones promueven. Conjuga flujos de deseo y experiencias estéticas que desplazan identidades y engendran un campo de creación permanente de formas de recepción de esta producción. Se concluye que este proceso resalta una tensión entre la dimensión molecular de la memoria, que se abre a la transversalidad de las concepciones de arte y locura, transformando el mapa de lo perceptible, y una dimensión molar, que destaca las tendencias de la clasificación en un segmento específico, o como producción directamente relacionada con un efecto social esperado oriundo de las iniciativas de la Reforma Psiquiátrica contra el estigma de la locura.

Palabras clave: Arte. Salud Mental. Memoria. Cultura. 


\section{REFERÊNCIAS}

AMARANTE, P.; FREITAS, F.; NABUCO, E. S.; PENDE, M. R. Da arteterapia nos serviços aos projetos culturais na cidade. In: AMARANTE, P; CAMPOS, F. N.(Org.) Saúde Mental e Arte: Práticas, saberes e debates. São Paulo: Zagodoni, 2012, p. 23-38.

AMARANTE, P.; COSTA, A. M. Diversidade cultural e saúde. Rio de Janeiro: Cebes, 2012.

BARBOSA, N. D. Fendas na Cultura: a produção de tecnologias de participação socioculturais em Terapia Ocupacional. 2010. 234 f. Dissertação (Mestrado em Ciências) - Faculdade de Medicina da USP, São Paulo, 2010.

BARROS, D. D.; ALMEIDA, M. C.; VECCHIA, T. C. Terapia Ocupacional social: diversidade, cultura e saber técnico. Revista de Terapia Ocupacional da USP, São Paulo, v.18, n. 3, p. 128-134, set./dez. 2007.

BOTTI, N. C. L.; TORRÉZIO, M. C. S. Festival da loucura e a dimensão sociocultural da Reforma Psiquiátrica. Psicologia \& Sociedade; 26(n. spe.), p.212-221, 2014.

BRANCO, H. No Centro da Vida. Folheto de divulgação. 4a Mostra de Artes Visuais No Centro da Vida. Rio de Janeiro: Instituto Franco Basaglia, 2009.

CASTRO, E. D.; SAITO, C. M.; DRUMOND, F. V. F.; LIMA, L. J. C. Ateliês de Corpo e Arte: inventividade, produção estética e participação sociocultural. Revista de Terapia Ocupacional da USP, São Paulo, v. 22, n. 3, p. 254-262, set./dez. 2011.

CASTRO, E. D.; ASANUMA, G. D.; BARBOSA, N. D.; GHIRARDI, M. I .G. Agenciamentos coletivos na experimentação do PACTO Trabalho. Cadernos de Terapia Ocupacional da UFSCar, São Carlos, v. 21, n. 1, p. 163-170, 2013.

DI RENZO, R. Arte e Saúde Mental: um episódio. In: MELO, W.; FERREIRA, A.P. (Org.) A sabedoria que a gente não sabe: arte e saúde mental. Rio de Janeiro: Espaço Artaud, 2011, p. 151-153.

GALVANESE, A. T. C.; NASCIMENTO, A. F.; D'OLIVEIRA, A. F. P. L. Arte, cultura e cuidado nos centros de atenção psicossocial. Revista de Saúde Pública, São Paulo, v. 47, n. 2 , p. $360-367,2013$. 
GONDAR, J. Cinco proposições sobre memória social. In: DODEBEI, V.; FARIAS, F.R.; GONDAR, J.; (Org.) Por que memória social? Rio de Janeiro: Híbrida/ Programa de pós Graduação em Memória Social da UNIRIO, 2015, p. 19-40.

JELIN, E. Los trabajos de la memória. Madri: Siglo XXI, 2002.

LAZZARATO, M. Puissances de l'invention: La psycologie economique da Gabriel Tarde contre l'economie politique. Paris: Les Empecheurs de Penser Ronde, 2002.

LIBERATO, M. T. C.; DIMENSTEIN, M. Arte, loucura e cidade: a invenção de novos possíveis. Psicologia \& Sociedade, Porto Alegre, v. 25, n. 2, p.272-281, 2013.

LIMA, E. M. F. A. Arte, Clínica e Loucura: territórios em mutação. São Paulo: Summus: FAPESP, 2009.

LIMA, E. M. F. A.; ISODA, N. M. T.; CASTRO, E. D. Processos de criação e de escrita: a experiência das Exposições IN PACTO. Interface - Comunicação, Saúde, Educação, Botucatu, v.16, n.40, p.287-91, jan./mar. 2012.

MALUF, J. C. G.; LOPES, I. C.; BICHARA, T. A. C.; SILVA, J. A.; VALENT, I. U.; BUELAU, R. M.; LIMA E. M. F. A. O Coral Cênico Cidadãos Cantantes. Revista de Terapia Ocupacional da USP, São Paulo, v. 20, n. 3, p. 199-204, set./dez. 2009.

MILHOMENS, A. E.; LIMA, E. M. F. A. Recepção estética de apresentações teatrais com atores com história de sofrimento psíquico. Interface - Comunicação, Saúde, Educação, Botucatu, v. 18, n.49, p.377-88, 2014.

RAMOS, C. G. M.; TEIXEIRA, I.; NUNES, J. R.; MENEZES, M. P.; MELO, V. M. Arte (en)cena: humanização \& loucura. Polis e Psique, Porto Alegre, v. 2, n. temático, p. 208-221, 2012.

RANCIĖRE, J. O espectador emancipado. São Paulo: Martins Fontes, 2012.

SANTOS, N. A.; ROMAGNOLI, R. C. Quando a invenção pede passagem: ritmo e corpo nas oficinas de teatro do Centro de Referência em Saúde Mental (CERSAM) Noroeste de Belo Horizonte. Mental. Barbacena-MG, ano X, n. 18, p. 29-52, jan./jun. 2012. 
SILVA, A T. M. C.; AMARANTE, P.; GOMES, A. L. C.; BRAGA, J. E. F.; VALENÇA, A. M. G.; PADILHA, W. W. N. A propósito da Diversidade, Cultura e Saúde Mental: Novas Dimensões para a Compreensão da Loucura. Revista Brasileira de Ciências da Saúde, João Pessoa, v. 16, n. 3, p. 435- 438, 2012.

SIMÕES, W. Ovo de pisca-pisca ou acho que o título é dispensável, o que você acha? In: SECRETARIA MUNICIPAL DE SAÚDE - PREFEITURA DE BELO HORIZONTE. Mostra de Arte Insensata. Catálogo de exposição. Belo Horizonte: Secretaria Municipal de Saúde - BH, 2008.

STREPPEL, F. F.; PALOMBINI, A. L. Devir-loucura na rádio: uma experiência em saúde mental. Fractal: Revista de Psicologia, Niterói, v. 23, n. 3, p. 501-522, set./dez. 2011.

TARDE, G. As Leis da Imitação. Porto, Portugal: Rès- Editora, 2000.

THEMUDO, T. S. Gabriel Tarde: Sociologia e Subjetividade. Rio de Janeiro: Relume Dumará, 2002.

THOMAZONI, A. R.; FONSECA, T. M. G. Encontros Possíveis entre Arte, Loucura e Criação. Mental, Barbacena-MG, ano IX, n. 17, p. 605-620, jul./dez. 2011.

VARGAS, E. Antes Tarde do que nunca: Gabriel Tarde e a emergência das ciências sociais. Rio de Janeiro: Contracapa, 2000.

VIDAL, V. Cancioneiros do IPUB. In: MELO, W.; FERREIRA, A.P. (Org.) A sabedoria que a gente não sabe: arte e saúde mental. Rio de Janeiro: Espaço Artaud, 2011, p. 192-198.

XISTO, V. "Coletivo Carnavalesco Tá pirando, pirado, pirou!": desinstitucionalização e estratégias de sobrevivência dos profissionais de saúde mental. In: MELO, W.; FERREIRA, A. P. (Org.) A sabedoria que a gente não sabe: arte e saúde mental. Rio de Janeiro: Espaço Artaud, 2011, p. 181-191.

WANDERLEY, L. Recentemente. Folheto de divulgação $4^{\mathrm{a}}$ Mostra de Artes Visuais No Centro da Vida. Rio de Janeiro: Instituto Franco Basaglia, 2009.

\section{Artigo:}

Recebido em 19 de Maio de 2016.

Aceito em 03 de Março de 2017. 